\title{
Fathers' parenting self-efficacy during the transition to parenthood
}

\author{
Tiago Miguel Pinto, Bárbara Figueiredo (D), Luis L. Pinheiro and Catarina Canário \\ School of Psychology, University of Minho, Braga, Portugal
}

\begin{abstract}
Background: Little is known about the development of fathers parenting self-efficacy during the transition to parenthood.

Objectives: To analyse (1) fathers' parenting self-efficacy developmental path and (2) the effects of anxious and depressive symptoms and coparenting support on fathers' parenting self-efficacy developmental path, from the first trimester of pregnancy to 6 months postpartum.

Methods: Eighty-six fathers recruited at the first trimester of pregnancy completed self-report measures of anxious and depressive symptoms, coparenting support and parenting self-efficacy at the first and third trimesters of pregnancy, and at 1 and 6 months postpartum. Growth curve models were performed.

Results: An increase in fathers' parenting self-efficacy was found from the first trimester of pregnancy to 6 months postpartum. The main effects of anxious symptoms and interaction effects of anxious symptoms and time were found on fathers' parenting self-efficacy. Fathers with higher anxious symptoms revealed lower levels of parenting self-efficacy at the first trimester of pregnancy and a lower increase of parenting self-efficacy from this time to 6 months postpartum. The main effects of coparenting support were found in fathers' parenting self-efficacy. At the first trimester of pregnancy, fathers who perceived more coparenting support revealed higher levels of parenting self-efficacy.

Conclusion: The present study may contribute to the literature by describing fathers' parenting self-efficacy developmental path and the effects of anxious symptoms and coparenting support on fathers' parenting self-efficacy developmental path during the transition to parenthood.
\end{abstract}

\section{ARTICLE HISTORY}

Received 26 March 2015

Accepted 17 February 2016

\section{KEYWORDS}

Transition to parenthood;

fathers; parenting self-

efficacy; anxious and depressive symptoms; coparenting support

\section{Introduction}

Developmental transitions are long-term processes that result in a qualitative reorganization of individuals, involving internal and external changes. Internal changes modify the way that individuals understand and feel about themselves and the world. External changes compel individuals to reorganise their skills (at individual and familiar level) in order to adjust to their new roles and their relationships with significant others (e.g. Cowan \& Cowan, 2000). The transition to parenthood is a major developmental transition, compelling men and 
women to perform several developmental tasks in order to adapt to a wide range of biological, psychological and sociocultural changes and to be prepared for parenting (e.g. Cowan \& Cowan, 2000; Figueiredo \& Conde, 2011). A positive resolution of these developmental tasks leads to a complete transition to parenthood, to individual psychological adjustment and development, and adequate parenting. Contrarily, a negative resolution leads to an incomplete transition, an increase of psychopathological symptoms, and inadequate parenting.

Studies have reported a wide range of changes in different dimensions of individual development during the transition to parenthood - in self-identity, partner's relationship and extended family relationships (e.g. Bost, Cox, Burchinal, \& Payne, 2002; Katz-Wise, Priess, \& Hyde, 2010; Mitnick, Heyman, \& Smith Slep, 2009). Other studies have described how an incomplete transition negatively impacts men's and women's psychological adjustment and parenting (e.g. Figueiredo \& Conde, 2011; Parfitt \& Ayers, 2014).

The development of a parental identity may be a major developmental task of the transition to parenthood (e.g. Cowan \& Cowan, 2000). Parenting self-efficacy may be an important psychological process involved in the performance of this developmental task. However, little is known about the development of fathers' parenting self-efficacy during the transition to parenthood.

Bandura's (1997) social cognitive theory defined parenting self-efficacy as a parent's belief about his/her competence to perform parenting tasks, namely to feed, soothe and play with their infant (e.g. Coleman \& Karraker, 2003; Črnčec, Barnett, \& Matthey, 2008; Jones \& Prinz, 2005; de Montigny \& Lacharité, 2005). Parenting self-efficacy is not a personality trait but rather a dynamic and emerging process modified by individual factors, changing tasks and situational demands (Bandura, 1989). Bandura's (1997) social cognitive theory suggested that four dimensions shape the development of parenting self-efficacy: enactive mastery experiences, vicarious experiences, verbal persuasion and physiological and affective moods.

Affective moods may activate a selective recall of negative cognitions and past failures, which impair adaptive capacities (Bandura, 1989). Therefore, parents with high anxious and depressive symptoms may experience a lack of control and stressful cognitions, which result in negative judgements about their ability to cope with the challenges of the transition to parenthood (e.g. Kuhn \& Carter, 2006). A previous study reported that fathers with higher depressive symptoms during the postpartum period showed lower levels of parenting self-efficacy (e.g. Salonen et al., 2009).

Several studies have showed an increase of anxious and depressive symptoms during fathers' transition to parenthood (e.g. Figueiredo \& Conde, 2011; Parfitt \& Ayers, 2014). However, little is known about the possible effects of anxious and depressive symptoms on fathers' parenting self-efficacy developmental path during the transition to parenthood.

Verbal persuasion, specifically the support from significant others, may be an important resource for the development of parenting self-efficacy (Bandura, 1989). Individuals who felt higher levels of support from others tended to maintain their beliefs about efficacy (e.g. Bandura, 1989; Hudson, Campbell-Grossman, Fleck, Elek, \& Shipman, 2003). Thus, parents who felt higher levels of support from the other parent may increase their positive beliefs about parenting efficacy. Coparenting support is defined as the support from one partner to another in matters related to parenting (e.g. Feinberg, 2003; Feinberg, Brown, \& Kan, 2012). Studies have reported effects of coparenting support and agreement on fathers' adjustment during the transition to parenthood (e.g. Don, Biehle, \& Mickelson, 2013; Solmeyer \& Feinberg, 
2011). The way that each parent supports the other in his/her parenting may promote the development of parenting self-efficacy during the transition to parenthood. Nevertheless, to our knowledge, no study has addressed the possible effect of coparenting support on fathers' parenting self-efficacy developmental path.

Parenting self-efficacy was associated with better parenting and better child development (e.g. Coleman \& Karraker, 2003; Hudson, Elek, \& Fleck, 2001; Sanders \&Woolley, 2005). Fathers who perceive themselves as more capable to execute parenting tasks tend to be more successful in their parenting and fathers who are more successful in their parenting tend to perceived themselves as more capable to execute parenting tasks (e.g. Hudson et al., 2001).

This study aimed to analyse (1) fathers' parenting self-efficacy developmental path and (2) the effects of anxious and depressive symptoms and coparenting support on fathers' parenting self-efficacy developmental path, from the first trimester of pregnancy to 6 months postpartum. Accomplishing the aims of this study may clarify the psychological processes involved in the development of fathers' parenting self-efficacy during the transition to parenthood. According to Bandura's (1997) social cognitive theory and previous reports (e.g. Figueiredo \& Conde, 2011; Parfitt \& Ayers, 2014; Salonen et al., 2009), we expected fathers with more anxious and depressive symptoms to show lower levels of parenting self-efficacy at the first trimester of pregnancy and a lower increase of parenting self-efficacy during the transition to parenthood. We also expected that fathers with more coparenting support would show higher levels of parenting self-efficacy at the first trimester of pregnancy and a higher increase of parenting self-efficacy during the transition to parenthood. In this study, only two dimensions of Bandura's (1997) social cognitive theory were analysed - affective moods and verbal persuasion. Previous literature has suggested the importance of these two dimensions when analysing fathers' parenting self-efficacy transition to parenthood, mainly affective moods (e.g. Figueiredo \& Conde, 2011; Parfitt \& Ayers, 2014; Salonen et al., 2009).

\section{Method}

\section{Participants}

The sample was comprised of 86 primiparous fathers recruited at the first trimester of pregnancy in two Health Services in Portugal. Exclusion criteria were: unable to read or write in Portuguese, lived in Portugal for less than 10 years, multiparous fathers, multiple gestations, and pregnancies with gestational problems. From the 130 participants contacted, 121 (93.1\%) agreed to participate and 91 (70.0\%) signed an online informed consent form. From the 86 participants who completed the first assessment, 51 (59.3\%) completed all the assessments.

Nearly all participants were Portuguese (96.7\%), Caucasian (87.9\%) and Catholic (98.9\%). More than half were aged between 30 and 39 years old $(62.6 \%, M=31.25, S D=4.52)$, belonged to a high and medium socioeconomic level (59.0\%), and were employed in manual (qualified or not) professions for more than seven years (55.3\%). The majority were married and cohabiting (92.3\%), lived with the partner without any other family members in the household (76.9\%), and had a good and very good pregnancy acceptance $(89.0 \%)$ (see Table 1).

No significant associations and differences were found between participants that completed and did not complete all the assessments on nationality, ethnicity, religion, age, 
Table 1. Fathers' sociodemographic characteristics at the first trimester of pregnancy (baseline).

\begin{tabular}{lcc}
\hline & & $N=86$ \\
Characteristic & & $\%$ \\
\hline Age (years) & $20-29$ & 35.2 \\
& $30-39$ & 62.6 \\
Socioeconomic level & $40-45$ & 2.2 \\
& High & 33.3 \\
& Medium high & 14.1 \\
Professional status & Medium & 25.7 \\
& Medium low & 19.2 \\
Education (in years) & Low & 7.7 \\
& Employed & 89.0 \\
Matrimonial status & Unemployed & 8.8 \\
& Household or student & 2.2 \\
Household & $<9$ & 9.9 \\
& $9-12$ & 52.7 \\
Pregnancy acceptance & $>12$ & 37.4 \\
& Married & 63.7 \\
& Cohabitation & 28.6 \\
& Single & 7.7 \\
& Partner & 76.9 \\
& Partner and family & 13.2 \\
& Family (only) & 7.7 \\
\end{tabular}

socioeconomic level, professional status, education, matrimonial status and household. Significant associations were found on pregnancy acceptance, $x^{2}(4)=13.05, p=.011$. Participants who completed all the assessments tended to report a good and very good pregnancy acceptance at the first trimester of pregnancy. No significant differences were found on parenting self-efficacy, anxious symptoms, depressive symptoms and coparenting support scores at all the assessment waves.

\section{Procedure}

This study was conducted in accordance with the Helsinki Declaration and received previous approval from the University of Minho Ethical Commission. Participants were recruited in two Obstetrics outpatients units after the first ultrasound of the foetus (8-14 gestational weeks). The aims and the procedures were explained. Four online assessments were performed: (1) first trimester of pregnancy (8-14 gestational weeks), (2) third trimester of pregnancy (28-32 gestational weeks), (3) 1 month postpartum (2-4 weeks postpartum), and (4) 6 months postpartum (24-26 weeks postpartum). In all assessments participants completed the same measures.

\section{Measures}

\section{Sociodemographic characteristics}

Information about the participants was collected using a sociodemographic questionnaire (Figueiredo, Teixeira, Conde, Pinto, \& Sarmento, 2009). 


\section{Anxious symptoms}

The State-Trait Anxiety Inventory (Spielberger, Gorsuch, Lushene, Vagg, \& Jacobs, 1983) is a self-report scale composed by two subscales, the state anxiety (STAI-S) and the trait anxiety, each comprised by 20 items scored on a four-point Likert scale. The STAI-S that measures the temporary condition of 'state anxiety' was used to assess anxious symptoms. Several studies have used this measure with fathers during pregnancy and the postpartum period (e.g. Figueiredo \& Conde, 2011; Figueiredo et al., 2008). STAI-S Portuguese version showed good internal consistency (Cronbach's alpha ranged from .87 to .93) (Biaggio, Natalicio, \& Spielberger, 1976). In the present sample, Cronbach's alpha was .87.

\section{Depressive symptoms}

The Edinburgh Postnatal Depression Scale (EPDS; Cox, Holden, \& Sagovsky, 1987) was used to assess depressive symptoms. EPDS is a self-report scale comprised by 10 items scored on a four-point Likert scale designed to assess postpartum depression. This measure assesses the intensity of depressive symptoms within the previous seven days and was used in several studies with fathers during pregnancy and the postpartum period (e.g. Figueiredo \& Conde, 2011; Parfitt \& Ayers, 2014). EPDS Portuguese version showed good internal consistency (Cronbach's alpha $=.88$ ). In the present sample, Cronbach's alpha was .83.

\section{Coparenting support}

The Coparenting Relationship Scale - Prenatal Version (CRS-PV); was used to assess coparenting support. CRS-PV is a prenatal version of the Coparenting Relationship Scale (Feinberg et al., 2012). This measure is a self-report scale comprised by 30 items scored on a seven-point Likert scale designed to assess coparenting during pregnancy and is composed by four subscales that assesses four dimensions of coparenting: (1) the coparenting support subscale, which assesses one's perception of coparental support from the other coparent (e.g. 'My partner makes me feel like I will be the best possible parent for our child'); (2) the coparenting conflict subscale, which assesses coparents' perception about exposing the infant to conflicts related to their education (e.g.'Do you find yourself in a mildly tense or sarcastic interchange with your partner?'); (3) the coparenting disagreement subscale, which assesses the degree to which each coparent will disagree with matters related to the infant (e.g. 'My partner and I have the same goals for our child'); and (4) the coparenting undermining subscale, which assesses one's perception that coparenting will be regulated by critics, guilty and competition between the coparents (e.g. 'My partner does not trust my abilities as a parent'). The CRS-PV showed good internal consistency (Cronbach's alpha $=.85$ for total scale; .94 for the coparenting support subscale; .90 for the coparenting conflict subscale; .79 for the coparenting disagreement subscale; and .69 for the coparenting undermining subscale). In the present sample, Cronbach's alpha was .87 for the coparenting support subscale.

\section{Parenting self-efficacy}

The Portuguese version of the Karitane Parenting Confidence Scale (KPCS; Črnčec et al., 2008) was used to assess parenting self-efficacy. KPCS is a self-report measure comprised by 15 items (e.g. 'I am confident about feeding my baby';'I can settle my baby') scored on a fourpoint Likert scale designed to assess to parenting self-efficacy. Higher scores on KPCS indicate higher parenting self-efficacy. This measure showed good internal consistency (Cronbach's alpha = .81). 
The Portuguese version of KPCS is based on Portuguese spoken and written in Portugal. All KPCS items were translated to Portuguese and back-translated to English. KPCS Portuguese version showed good internal consistency (Cronbach's alpha $=.85)$. In the present sample, Cronbach's alpha was .84.

\section{Data analytic strategy}

Growth curve models were estimated using multilevel modelling (e.g. Duncan, Duncan, \& Strycker, 2006) to (1) analyse fathers' parenting self-efficacy developmental path and (2) explore effects of anxious and depressive symptoms, and coparenting support on fathers' parenting self-efficacy developmental path from the first trimester of pregnancy to 6 months postpartum. An important issue when modelling growth curves is the scaling of time (e.g. Biesanz, Deeb-Sossa, Papadakis, Bollen, \& Curran, 2004). Time 0 was defined as the date of the first assessment at the first trimester of pregnancy (baseline) and the time variable was scored in weeks since the baseline until 6 months postpartum. The intercept refers to the outcome variable (fathers' parenting self-efficacy) at the baseline and the slope for time represents the extent to which the outcome variable changes each week. Scale scores for parenting self-efficacy, anxious and depressive symptoms, and coparenting support were examined at each assessment wave. Fixed effects for anxious and depressive symptoms and coparenting support (time-varying effects centred on their grand means) were included in the models. Different models were performed for each outcome variable. Preliminary analyses revealed larger size correlations between anxious and depressive symptoms (see Table 3) so were included in the same model. Pregnancy acceptance at the first trimester of pregnancy was included as a covariate in all the models. Significant interactions with continuous predictors were interpreted and graphed using one standard deviation above and below the grand mean of the predictor variables as high and low values. Deviance difference tests were performed between unconditional models and models with predictors to examine model fit improvements.

Statistical analyses were performed in a pairwise person-period data set using SPSS version 22.0 (SPSS Inc., USA). Each participant had a record for each time point. The resulting data consisted of 344 potential observations ( 86 participants by four time points). The effect size $r$ (Rosenthal, Rosnow, \& Rubin, 2000) was estimated for all significant effects and interpreted according to Cohen's guidelines (Cohen, 1988).

\section{Results}

\section{Preliminary results}

Descriptive statistics for all study variables at each assessment were performed (see Table 2). Significant small to large size correlations were found among the study variables at each assessment wave, revealing that these scores covary (see Table 3). Higher size correlations were found among the study variables at the first and third trimester of pregnancy. Deviance difference tests showed that the models provided good fit to the data, $X^{2}(1)=10.12$, $p=.006$, and $, X^{2}(1)=16.02, p=.003$. 
Table 2. Descriptive statistics of study variables across time.

\begin{tabular}{|c|c|c|c|c|c|c|c|c|}
\hline & \multicolumn{4}{|c|}{ Pregnancy } & \multicolumn{4}{|c|}{ Postpartum } \\
\hline & \multicolumn{2}{|c|}{ First trimester } & \multicolumn{2}{|c|}{ Third trimester } & \multicolumn{2}{|c|}{ One month } & \multicolumn{2}{|c|}{ Six months } \\
\hline & $M$ & $S D$ & $M$ & $S D$ & $M$ & $S D$ & $M$ & $S D$ \\
\hline Parenting self-efficacy & 34.99 & 5.71 & 37.29 & 4.88 & 39.06 & 4.51 & 39.80 & 5.35 \\
\hline Anxious symptoms & 31.91 & 7.07 & 35.37 & 7.51 & 30.42 & 8.14 & 31.79 & 7.14 \\
\hline Depressive symptoms & 3.76 & 3.31 & 3.89 & 3.42 & 2.83 & 3.25 & 3.30 & 2.98 \\
\hline Coparenting support & 85.32 & 12.19 & 82.95 & 11.80 & 80.76 & 14.54 & 75.55 & 17.78 \\
\hline
\end{tabular}

Notes: $M=$ Mean; $S D=$ Standard deviation.

Table 3. Correlations among the study variables at each assessment wave.

\begin{tabular}{|c|c|c|c|c|}
\hline First trimester of pregnancy & 1 & 2 & 3 & 4 \\
\hline 1. Parenting self-efficacy & 1.00 & & & \\
\hline 2. Anxious symptoms & $-.440 * *$ & 1.00 & & \\
\hline 3. Depressive symptoms & $-.413^{* *}$ & $.712^{* * *}$ & 1.00 & \\
\hline 4. Coparenting support & $.483^{* *}$ & $-.389 * *$ & $-.437^{* *}$ & 1.00 \\
\hline Third trimester of pregnancy & 1 & 2 & 3 & 4 \\
\hline 1. Parenting self-efficacy & 1.00 & & & \\
\hline 2. Anxious symptoms & $-.472^{* *}$ & 1.00 & & \\
\hline 3. Depressive symptoms & $-.413^{* *}$ & $.440^{* * *}$ & 1.00 & \\
\hline 4. Coparenting support & $.483^{* *}$ & $-.389 * *$ & $-.437^{* *}$ & 1.00 \\
\hline One month postpartum & 1 & 2 & 3 & 4 \\
\hline 1. Parenting self-efficacy & 1.00 & & & \\
\hline $\begin{array}{l}\text { 2. Anxious symptoms } \\
\text { s ymom }\end{array}$ & $-.434^{* *}$ & 1.00 & & \\
\hline 3. Depressive symptoms & $-.370^{* *}$ & $.572^{* * *}$ & 1.00 & \\
\hline 4. Coparenting support & $.386^{* *}$ & $-.343^{* *}$ & $-.401^{* *}$ & 1.00 \\
\hline Six months postpartum & 1 & 2 & 3 & 4 \\
\hline 1. Parenting self-efficacy & 1.00 & & & \\
\hline 2. Anxious symptoms & $-.388^{* *}$ & 1.00 & & \\
\hline 3. Depressive symptoms & $-.268^{*}$ & $.395^{* *}$ & 1.00 & \\
\hline 4. Coparenting support & $.275^{*}$ & $-.378^{* *}$ & $-.320^{* *}$ & 1.00 \\
\hline
\end{tabular}

${ }^{*} p<.05 ;{ }^{* *} p<.01 ;{ }^{* * *} p<.001$.

\section{Fathers' parenting self-efficacy developmental path from the first trimester of pregnancy to 6 months postpartum}

The main effects for time were found in fathers' parenting self-efficacy (see Table 4). From the first trimester of pregnancy to 6 months postpartum, fathers' parenting self-efficacy increased, on average, 0.08 units per week, $p<.001$, effect size $r=.304$.

The effects of anxious and depressive symptoms, and coparenting support on fathers' parenting self-efficacy developmental path from the first trimester of pregnancy to 6 months postpartum

The main effects of anxious symptoms were found in fathers' parenting self-efficacy (see Table 4). At the first trimester of pregnancy, fathers with higher anxious symptoms showed lower levels of parenting self-efficacy, $b=-0.24, p=.002$, effect size $r=.239$. Moreover, interaction effects of anxious symptoms and time were also found, suggesting a moderator effect of anxious symptoms on fathers' parenting self-efficacy developmental path from the first trimester of pregnancy to six months postpartum (see Table 4 and Figure 1). Fathers with higher anxious symptoms showed a lower increase of parenting self-efficacy from the first trimester of pregnancy to 6 months postpartum, $b=-0.01, p=.027$, effect size $r=.139$. 
Table 4. Fathers' parenting self-efficacy developmental path from the first trimester of pregnancy to 6 months postpartum: effects of anxious and depressive symptoms, and coparenting support.

\begin{tabular}{lrcc}
\hline & \multicolumn{3}{c}{ Parenting self-efficacy } \\
\cline { 2 - 4 } Fixed effects & $b$ & $S E$ & $95 \% \mathrm{Cl}$ \\
\hline Intercept & 39.54 & 0.50 & {$[38.55,40.52]^{* * *}$} \\
Time & 0.08 & 0.02 & {$[0.05,0.11]^{* * * *}$} \\
Anxious symptoms & -0.24 & 0.07 & {$[-0.38,-0.09]^{* *}$} \\
Depressive symptoms & -0.28 & 0.18 & {$[-0.63,0.08]$} \\
Coparenting support & 0.11 & 0.03 & {$[0.06,0.17]^{* * *}$} \\
Anxious symptoms $\times$ Time & -0.01 & 0.01 & {$[-0.01,-0.00]^{*}$} \\
Depressive symptoms $\times$ Time & -0.00 & 0.01 & {$[-0.01,0.01]^{*}$} \\
Coparenting support $\times$ Time & 0.00 & 0.00 & {$[-0.00,0.00]$} \\
Random effects & & & {$[0.00,0.01]^{* * *}$} \\
Intercept + Time & 0.01 & 0.00 & {$[14.51,22.43]^{* * *}$} \\
Residuals & 18.04 & 2.00 & \\
\hline
\end{tabular}

Notes: $S E=$ Standard error; $\mathrm{Cl}=$ Confidence interval; pregnancy acceptance at the first trimester of pregnancy was included was a covariate.

${ }^{*} p<.05 ;{ }^{* *} p<.01 ;{ }^{* * *} p<.001$.

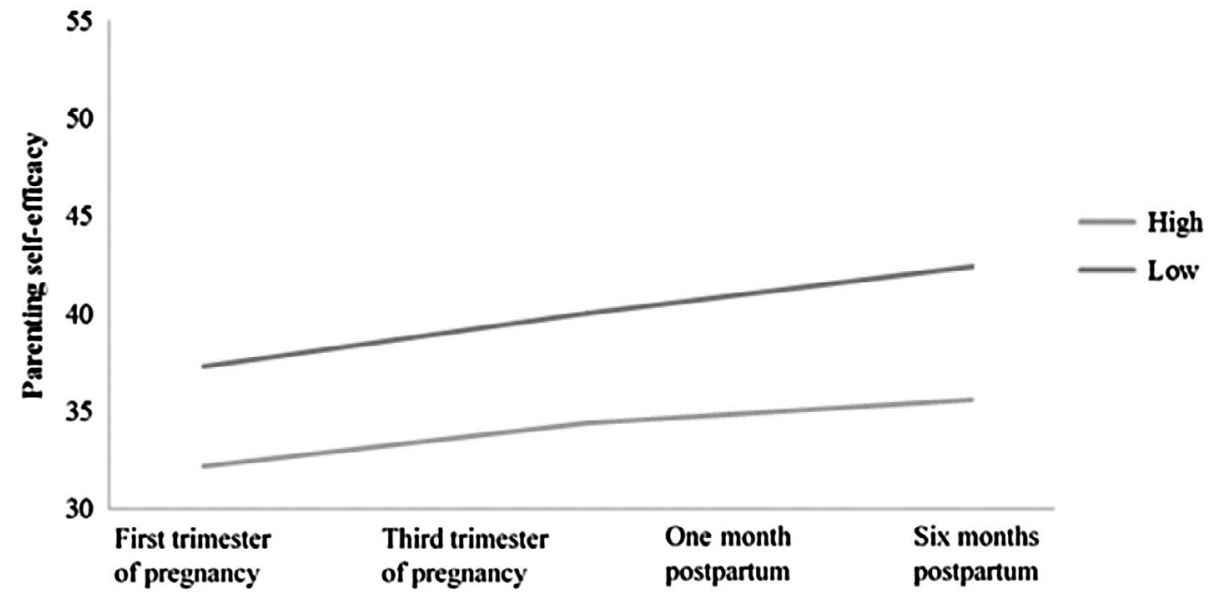

Assessement waves

Figure 1. Parenting self-efficacy developmental paths from the first trimester of pregnancy to 6 months postpartum of fathers with high and low anxious symptoms.

The main effects of coparenting support were found in fathers' parenting self-efficacy (see Table 4). At the first trimester of pregnancy, fathers who perceived more coparenting support from their coparent showed higher levels of parenting self-efficacy, $b=0.11, p<.001$, effect size $r=.289$. No interaction effects of coparenting support and time were found. No effects of depressive symptoms were found (see Table 4).

\section{Discussion}

This study analysed fathers' parenting self-efficacy developmental path and the effects of anxious and depressive symptoms and coparenting support on fathers' parenting self-efficacy developmental path from the first trimester of pregnancy to 6 months postpartum. The main time effects on father's parenting self-efficacy were found. Results showed an 
increase on fathers' parenting self-efficacy from the first trimester of pregnancy to 6 months postpartum and suggested that, while transiting to parenthood, fathers tend to perceive themselves as more capable of executing a wide range of parenting tasks. This result extends to fathers' recent data on the increase of mothers' parenting self-efficacy during the transition to parenthood (Wernand, Kunseler, Oosterman, Beekman, \& Schuengel, 2014). The increase observed in fathers' parenting self-efficacy gives evidence to the idea that parenting self-efficacy can be an important psychological process involved in fathers' transition to parenthood.

The main effects of anxious symptoms and interaction effects of anxious symptoms and time were found on fathers' parenting self-efficacy, suggesting a moderator effect of anxious symptoms on fathers' parenting self-efficacy developmental path from the first trimester of pregnancy to six months postpartum. At the first trimester of pregnancy, fathers with higher anxious symptoms showed lower levels of parenting self-efficacy. Moreover, fathers with higher anxious symptoms showed a lower increase of parenting self-efficacy from the first trimester of pregnancy to 6 months postpartum. Extending recent data on mothers' parenting self-efficacy during the transition to parenthood (Wernand et al., 2014), this result suggested that anxious symptoms negatively moderate the increase observed on fathers' parenting self-efficacy over time. Father's high anxiety appears to interfere with the development of parenting self-efficacy, an important psychological process to complete the transition to parenthood and to adequate parenting (e.g. Cowan \& Cowan, 2000; Hudson et al., 2001). During this period, fathers with higher anxious symptoms may experience a lack of control and stressful cognitions, which may result in negative judgements about their ability to cope with the challenges of parenting (e.g. Kuhn \& Carter, 2006).

No effects of depressive symptoms were found on fathers' parenting self-efficacy. During the transition to parenthood, fathers have to adapt to major changing processes (e.g. Bost et al., 2002; Katz-Wise et al., 2010; Mitnick et al., 2009), from which can arise uncertainty, emotional arousal and anxiety about future responsibilities (e.g. Delmore-Ko, Pancer, Hunsberger, \& Pratt, 2000). Studies suggested that despite the cognitive processes involved in anxiety and depression being similar, each psychopathology is characterised by specific cognitions (e.g. MacLeod, Tata, Kentish, \& Jacobsen, 1997; Mineka, Watson, \& Clark, 1998; Stober, 2000). Depressive cognitions seem to be predominantly associated with memory bias for negative experiences and low positive expectations about the future in general (e.g. Mineka et al., 1998). Conversely, anxious cognitions appear to be more future-oriented and characterised by an attentional bias for anxiety-provoking information and more negative expectations in the context of a highly valued outcome (e.g. Stober, 2000), namely becoming a father. This could explain why we found effects of anxious symptoms but not of depressive symptoms.

The main effects of coparenting support were found on fathers' parenting self-efficacy. At the first trimester of pregnancy, fathers that perceived more coparenting support from their coparent in matters related with parenting perceived themselves as more capable to execute parenting tasks. A previous study reported a positive association between coparenting support and fathers' adjustment during the postpartum period (Solmeyer \& Feinberg, 2011). The present study suggested that support from the coparent is an important strength for the development of fathers' parenting self-efficacy at the first trimester of pregnancy and seems to beneficiate important psychological processes involved in the beginning of the transition to parenthood. However, no interaction effects of coparenting support and time 
were found on fathers' parenting self-efficacy developmental path. Previous studies reported that coparenting support presents high stability over time (e.g. McHale \& Rotman, 2007). This could explain why no effects over time were found.

Our results may add new empirical evidence to Bandura's (1997) social cognitive theory during the transition to parenthood. Anxious symptoms (affective mood) and coparenting support (verbal persuasion) were found to be dimensions that influence the development of fathers' parenting self-efficacy during the transition to parenthood.

\section{Limitations}

Some methodological limitations can be pointed out. The voluntary nature of the participation may have led to a selection bias, because those who agreed to participate and those who complied on all assessments may be those who feel more involved and satisfied with the pregnancy and the postpartum experience. Sample sociodemographics may be biased (e.g. low-risk, higher-educated). This should be taken into account when considering the generalisation of findings to other populations of fathers. Participants who completed all the assessments were more likely to report a good and very good pregnancy acceptance at the first trimester of pregnancy. Pregnancy acceptance at the first trimester of pregnancy was included as a covariate in the analysis. A larger sample size could increase the power of the analysis. Constructs were assessed through self-report measures. Despite all measures exhibiting adequate internal consistency, additional observational measures could have contributed to a higher accuracy and reduced the possible shared method variance on the study variables.

\section{Implications for practice and research}

This study suggests effects of anxious symptoms and coparenting support on the development of fathers' parenting self-efficacy during the transition to parenthood, an important developmental task to accomplish this developmental transition. The moderator effect of anxious symptoms on the development of fathers' parenting self-efficacy appears to be a major, clinically relevant finding. Despite a small effect, fathers with high anxious symptoms show a lower increase in their belief about their ability to perform parenting tasks during the transition to parenthood. New preventive interventions on the transition to parenthood could give more attention to fathers' anxiety and coparenting to enhance the development of fathers' parenting self-efficacy (e.g. Feinberg \& Kan, 2008). Future studies on the development of parenting self-efficacy during the transition to parenthood could explore possible dyadic effects (within the dyad) on fathers' and mothers' parenting self-efficacy developmental path.

\section{Conclusion}

This study showed three major findings on fathers' parenting self-efficacy: (1) during the transition to parenthood, fathers perceive themselves as more capable of performing parenting tasks; (2) fathers with high anxious symptoms perceive themselves as less capable of performing parenting tasks at the first trimester of pregnancy and a lower increase of parenting self-efficacy during the transition to parenthood; and (3) fathers who perceive 
more coparenting support from their partner perceive themselves as more capable of performing parenting tasks at the first trimester of pregnancy. The present study may contribute to the literature by describing fathers' parenting self-efficacy developmental path and the effects of anxious symptoms and coparenting support on fathers' parenting self-efficacy developmental path during the transition to parenthood.

\section{Disclosure statement}

No potential conflict of interest was reported by the authors.

\section{Funding}

This research was supported by FEDER Funds through the Programa Operacional Factores de Competitividade - COMPETE and by National Funds through FCT - Fundação para a Ciência e a Tecnologia under the project PTDC/SAU/SAP/116,738/2010.

\section{ORCID}

Bárbara Figueiredo (D) http://orcid.org/0000-0002-8209-7445

\section{References}

Bandura, A. (1989). Regulation of cognitive processes through perceived self-efficacy. Developmental Psychology, 25, 725-739. doi:http://dx.doi.org/10.1037/0003-066X.44.9.1175

Bandura, A. (1997). Self-efficacy: The exercise of control. New York, NY: Freeman.

Biaggio, A. M., Natalicio, L., \& Spielberger, C. D. (1976). The development and validation of an experimental Portuguese form of the State-Trait Anxiety Inventory. In C. D. Spielberger, \& R. DiasGuerrero (Eds.), Cross-cultural research on anxiety (pp. 29-40). Washington DC: Hemisphere/Wiley.

Biesanz, J. C., Deeb-Sossa, N., Papadakis, A. A., Bollen, K. A., \& Curran, P. J. (2004). The role of coding time in estimating and interpreting growth curve models. Psychological Methods, 9, 30-52. doi:http:// dx.doi.org/10.1037/1082-989X.9.1.30

Bost, K. K., Cox, M. J., Burchinal, M. R., \& Payne, C. (2002). Structural and supportive changes in couples' family and friendship networks across the transition to parenthood. Journal of Marriage and Family, 64, 517-531. doi:http://dx.doi.org/10.1111/j.1741-3737.2002.00517.x

Cohen, J. (1988). Statistical power analysis for the behavioral sciences (2nd ed.). New Jersey: Lawrence Erlbaum.

Coleman, P., \& Karraker, K. H. (2003). Maternal self-efficacy beliefs, competence in parenting, and toddlers' behavior and developmental status. Infant Mental Health Journal, 24, 126-148. doi:http:// dx.doi.org/10.1002/imhj.10048

Cowan, C., \& Cowan, P. (2000). When partners become parents: The big life change for couples. Mahwah, $\mathrm{NJ}$ : Lawrence Earlbaum.

Cox, J., Holden, J., \& Sagovsky, R. (1987). Detection of postnatal depression. Development of the 10item Edinburgh postnatal depression scale. The British Journal of Psychiatry, 150, 782-786. doi:http:// dx.doi.org/10.1192/bjp.150.6.782

Črnčec, R., Barnett, B., \& Matthey, S. (2008). Development of an instrument to assess perceived selfefficacy in the parents of infants. Research in Nursing \& Health, 31, 442-453. doi:http://dx.doi. org/10.1002/nur.20271

Delmore-Ko, P., Pancer, S. M., Hunsberger, B., \& Pratt, M. (2000). Becoming a parent: The relation between prenatal expectations and postnatal experience. Journal of Family Psychology, 14, 625-640. doi:http:// dx.doi.org/10.1037//0893-3200.14.4.625 
Don, B. P., Biehle, S. N., \& Mickelson, K. D. (2013). Feeling like part of a team perceived parenting agreement among first-time parents. Journal of Social and Personal Relationships, 30, 1121-1137. doi:http://dx.doi.org/10.1177/0265407513483105

Duncan, T., Duncan, S., \& Strycker, L. (2006). An introduction to latent growth curve modeling: Concepts, issues and applications (2nd ed.). New Jersey: Lawrence Erlbaum Associates.

Feinberg, M. (2003). The internal structure and ecological context of coparenting: A framework for research and intervention. Parenting:Science and Practice, 3, 85-132. doi:http://dx.doi.org/10.1207/ S15327922PAR0302_01

Feinberg, M. E., Brown, L. D., \& Kan, M. L. (2012). A multi-domain self-report measure of coparenting. Parenting: Science and Practice, 12, 1-21. doi:http://dx.doi.org/10.1080/15295192.2012.638870

Feinberg, M. E., \& Kan, M. L. (2008). Establishing family foundations: Intervention effects on coparenting, parent/infant well-being, and parent-child relations. Journal of Family Psychology, 22, 253-263. doi:http://dx.doi.org/10.1037/0893-3200.22.2.253

Figueiredo, B., \& Conde, A. (2011). Anxiety and depression symptoms in women and men from early pregnancy to 3-months postpartum: Parity differences and effects. Journal of Affective Disorders, 132, 146-157. doi:http://dx.doi.org/10.1016/j.jad.2011.02.007

Figueiredo, B., Field, T., Diego, M., Hernandez-Reif, M., Deeds, O., \& Ascencio, A. (2008). Partner relationships during the transition to parenthood. Journal of Reproductive and Infant Psychology, 26, 99-107. doi:http://dx.doi.org/10.1080/02646830701873057

Figueiredo, B., Teixeira, C., Conde, A., Pinto, A., \& Sarmento, P. (2009). Utentes da consulta externa de ginecologia/obstetrícia da Maternidade Júlio Dinis. Revista Portuguesa de Psicologia, 41, 45-64. Retrieved from http://hdl.handle.net/123456789/472

Hudson, D. B., Campbell-Grossman, C., Fleck, M. O., Elek, S. M., \& Shipman, A. (2003). Effects of the new fathers network on first-time fathers' parenting self-efficacy and parenting satisfaction during the transition to parenthood. Issues in Comprehensive Pediatric Nursing, 26, 217-229. doi:http://dx.doi. org/10.1080/01460860390246687

Hudson, D., Elek, M., \& Fleck, M. (2001). First-time mothers and fathers transition to parenthood: Infant care self-efficacy, parenting satisfaction, and infant sex. Issues in Comprehensive Pediatric Nursing, 24, 31-43. doi:http://dx.doi.org/10.1080/014608601300035580

Jones, T., \& Prinz, R. (2005). Potential roles of parental self-efficacy in parent and child adjustment: A review. Clinical Psychology Review, 25, 341-363. doi:http://dx.doi.org/10.1016/j.cpr.2004.12.004

Katz-Wise, S. L., Priess, H. A., \& Hyde, J. S. (2010). Gender-role attitudes and behavior across the transition to parenthood. Developmental Psychology, 46, 18-28. doi:http://dx.doi.org/10.1037/a0017820

Kuhn, J. C., \& Carter, A. S. (2006). Maternal self-efficacy and associated parenting cognitions among mothers of children with autism. American Journal of Orthopsychiatry, 76, 564-575. doi:http://dx.doi. org/10.1037/0002-9432.76.4.564

MacLeod, A., Tata, P., Kentish, J., \& Jacobsen, H. (1997). Retrospective and prospective cognitions in anxiety and depression. Cognition \& Emotion, 11, 467-479. doi:http://dx.doi.org/10.1080/026999397379881

McHale, J. P., \& Rotman, T. (2007). Is seeing believing? Expectant parents' outlooks on coparenting and later coparenting solidarity. Infant Behavior and Development, 30, 63-81. doi:http://dx.doi. org/10.1016/j.infbeh.2006.11.007

Mineka, S., Watson, D., \& Clark, L. A. (1998). Comorbidity of anxiety and unipolar mood disorders. Annual Review of Psychology, 49, 377-412.

Mitnick, D. M., Heyman, R. E., \& Smith Slep, A. M. (2009). Changes in relationship satisfaction across the transition to parenthood: A meta-analysis. Journal of Family Psychology, 23, 848-852. doi:http:// dx.doi.org/10.1037/a0017004

de Montigny, F., \& Lacharité, C. (2005). Perceived parental efficacy: Concept analysis. Journal of Advanced Nursing, 49, 387-396. doi:http://dx.doi.org/10.1111/j.1365-2648.2004.03302.x

Parfitt, Y., \& Ayers, S. (2014). Transition to parenthood and mental health in first-time parents. Infant Mental Health Journal, 35, 263-273. doi:http://dx.doi.org/10.1002/imhj.21443

Rosenthal, R., Rosnow, R. L., \& Rubin, D. B. (2000). Contrasts and effect sizes in behavioral research: A correlational approach. Cambridge: Cambridge University Press. 
Salonen, A. H., Kaunonen, M., Åstedt-Kurki, P., Järvenpää, A. L., Isoaho, H., \& Tarkka, M. T. (2009). Parenting self-efficacy after childbirth. Journal of Advanced Nursing, 65, 2324-2336. doi:http://dx.doi. org/10.1111/j.1365-2648.2009.05113.x

Sanders, M., \& Woolley, M. (2005). The relationship between maternal self-efficacy and parenting practices: implications for parent training. Child: Care, Health and Development, 31, 65-73. doi:http:// dx.doi.org/10.1111/j.1365-2214.2005.00487.x

Solmeyer, A. R., \& Feinberg, M. E. (2011). Mother and father adjustment during early parenthood: The roles of infant temperament and coparenting relationship quality. Infant Behavior and Development, 34, 504-514. doi:http://dx.doi.org/10.1016/j.infbeh.2011.07.006

Spielberger, C. D., Gorsuch, R. L., Lushene, R., Vagg, P. R., \& Jacobs, G. A. (1983). Manual for the state-trait anxiety inventory. STAI (Form Y). Palo Alto: Consulting Psychologists Press.

Stober, J. (2000). Prospective cognitions in anxiety and depression: Replication and methodological extension. Cognition \& Emotion, 14, 725-729. doi:http://dx.doi.org/10.1080/02699930050117693

Wernand, J., Kunseler, F., Oosterman, M., Beekman, A., \& Schuengel, C. (2014). Prenatal changes in parenting self-efficacy: Linkages with anxiety and depressive symptoms in primiparous women. Infant Mental Health Journal, 35, 42-50. doi:http://dx.doi.org/10.1002/imhj.21425 